\title{
Yeni Nesil Elektrik Dağıtım Şebekeleri İçin Çok Fonksiyonlu Dijital Aşırı Akım Rölesi Tasarımı ve Geliştirilmesi
}

\author{
Ender Oğuz ${ }^{*}$, Yavuz Ateş ${ }^{2}$, M. Metin Hekimoğlu ${ }^{1}$ \\ ${ }^{1}$ DATAKOM Elektronik Mühendislik San. Tic. A.Ş., İstanbul, Türkiye (ORCID: 0000-0000-0000-0000) \\ ${ }^{2}$ Yıldız Teknik Üniversitesi, Elektrik Mühendisliği Bölümü, İstanbul, Türkiye (ORCID: 0000-0000-0000-0000)
}

(İlk Geliş Tarihi 29 Temmuz 2019 ve Kabul Tarihi 25 Ağustos 2019)

(DOI: 10.31590/ejosat.597297)

ATIF/REFERENCE: Oğuz, E., Ateş, Y. \& Hekimoğlu, M. M. (2019). Yeni Nesil Elektrik Dağıtım Şebekeleri İçin Çok Fonksiyonlu Dijital Aşırı Akım Rölesi Tasarımı ve Geliştirilmesi. Avrupa Bilim ve Teknoloji Dergisi, (16), 915-924.

\section{$\ddot{O} \mathbf{z}$}

Elektrik enerjisinin üretimi, iletimi, dağıtımı ve tüketiminden oluşan süreçte; ekipmanların ve canlıların arızalara karşı korunması ve enerji kalitesinin sağlanması için koruma sistemlerinin doğru ve seçici bir şekilde çalışarak görevlerini süreklilikle yerine getirmeleri gerekmektedir. Ancak bu süreçte koruma sistemleri bazı hatalarla/arızalarla karşı karşıya kalmaktadır. Koruma sistemlerinin etkili oldukları bölgelerde işletme koşullarının değişmesi, koruma sistemlerinin farklı arızalara maruz kalmasına neden olmaktadır.

Seçicilik, süratli çalışma, güvenilirlik, yedek koruma, kararlılık, ekonomiklik gibi özellikleri taşıması beklenen koruma sistemleri uygun şekilde kurulmuş ve sürekli çalışır durumda olmalıdır. İşletmelerdeki besleme yönünün değişmesi, mevsimsel tüketim değişiklikleri gibi farklı senaryolara farklı şekilde uyum sağlayabilecek adaptif koruma sistemleri yeni nesil şebekelerin sürekliliği için elzemdir. Adaptif korumanın sağlanabimesi için koruma sisteminin en önemli elemanları olan rölelelerin yüksek teknolojiye sahip, birçok koruma özelliğini bir arada bulunduran akıllı donanımlar olmaları gerekmektedir.

Piyasadaki talep ve teknoloji gelişmeler doğrultusunda birçok fonksiyonu bir arada bulunduran yeni bir dijital koruma rölesi geliştirilmesi hedeflenmiştir. Bu hedefle bu rölenin, kontrol, ölçü ve koruma fonksiyonlarını içermesi; röle üzerindeki tuş takımı ve haberleşme portları üzerinden fonksiyonların aktif hale getirilebilmesi beklenmektedir. Ayrıca beklenen bir diğer özellik RS485 portu ile IEC 60870-5-103 protokolünü kullanarak iletişim yapabilmesi ve ethernet portu ile bir otomasyon sistemi içerisinde IEC 61850 standardına uygun haberleşme özelliklerini sağlamasıdır.

Hedeflenen cihazın hem analizör hem de koruma ekipmanı olarak çalışması sağlanmıştır. Cihaz "Düşük gerilim koruma (27)," Arıza yeri tespit edici (FL)", "Aşırı gerilim koruma (59N)"," Termik koruma (49)", Açma devresi denetimi (74TCS)" koruma özelliklerini tek bir donanımda sunmaktadır.

Ürün geliştirilirken mikroişlemci kullanımı ve programlanması, manyetik değişkenlerin ölçümü ve kontrolü, algoritma geliştirme, haberleşme protokollerine uyum sağlama, laboratuar ve saha testleri yapma yöntemlerinden faydalanılmıştır.

$\mathrm{Bu}$ çalışmada birçok koruma fonksiyonunun tek bir donanımda sunulduğu bir dijital koruma rölesinin tasarımı, gerçeklenmesi ve test edilmesi ile elde edilen sonuçlar verilmiştir.

Anahtar Kelimeler: Dijital Aşırı Akım Rölesi, Adaptif Koruma, Aşırı Akım Koruma, Koruma Rölesi

\section{Design and Development of Multifunctional Digital Overcurrent Relays for New Generation Electricity Distribution Networks}

\begin{abstract}
In the process consisting of generation, transmission, distribution and consumption of electrical energy; protection systems must perform their duties continuously and correctly in order to protect equipment and living creatures against failures and to ensure energy quality. However, in this process, protection systems encounter some faults. Changes in operating conditions in the regions where the protection systems are effective, causes the protection systems to be exposed to different faults.
\end{abstract}

\footnotetext{
*Sorumlu Yazar: DATAKOM Elektronik Mühendislik San. Tic. A.Ş., İstanbul, Türkiye, ender.oguz@datakom.com.tr
} 
The characteristics are expected from the protection systems, such as selectivity, rapid operation, reliability, backup protection, stability and economy should be properly installed and work in continuous operation. Adaptive protection systems can adapt to different scenarios such as change of feed direction in the operations and seasonal consumption changes. Because of this specialty adaptive protection systems are essential for the continuity of the new generation networks. In order to provide adaptive protection, the relays, which are the most important elements of the protection system, must be high-tech, intelligent equipment that combines many protection features.

In line with the demands in the market and technological developments, it is aimed to develop a new digital protection relay which incorporates many functions together. With this objective, it is expected from this relay containing control, measurement and protection functions. Also, it is ecptected the functions can be activated via the keypad and communication ports on the relay. In addition to this, it is expected that it can communicate with the RS485 port using the IEC 60870-5-103 protocol, and that it provides the communication features in accordance with the IEC 61850 standard in an automation system with its ethernet port.

The targeted device is can operate both as an analyzer and protection equipment. The protection features "Undervoltage Protection (27)," Fault Locater (FL)", "Overvoltage Protection (59N)"," Thermal Protection (49)", Trip Circuit Supervision (74TCS) are offered in a single hardware.

During product development, microprocessor usage and programming, measurement and control of magnetic variables, algorithm development, adaptation to communication protocols, laboratory and field tests were used.

In this study, the design, implementation and testing of a digital protection relay in which several protection functions are presented in a single hardware are given.

Keywords: Digital Overcurrent Relay, Adaptive Protection, Overcurrent Protection, Protection Relay

\section{Giriş}

Son yıllarda artan enerji talebiyle enerji hatlarının iletimde ve dağıtımda; kontrol ve koruma gereksinimlerini daha verimli ve daha etkin bir şekilde yapmak gereği ortaya çıkmıştır. Elektrik enerjisini kaynaktan kullanıcılara iletim ve dağıtım hatları ile aktarırken daha verimli ve kullanışlı, daha güvenlikli sistemler kurabilmek ve bu sistemlerin sürdürülebilir bir şekilde işletilmesini sağlamak için akıllı ve uzaktan kontrol sağlayabilen yapılar araştırılmaktadır.

Son kullanıcıların ve ekipmanların zarar görmemesi için güç sistemlerinde oluşan arızalara hızlı bir şekilde çözüm getirilmelidir. İlk yıllarda arızalara çözüm sunmak için teknik ekipler tarafından el ile müdahale edilip kesicilerin kontrolü sağlanmaktaydı. Zamanla sistemler ve arızalar büyüdükçe güvenlik ve hızlı olmak gereklilikleri açısından arızalara çözüm getirme işlemlerini otomatikleştirmek zorunluluğu ortaya çıkmıştır. Arızalara otomatik çözümler sunmada en temel olarak kullanılan elemanlar röleler, kesiciler ve sigortalardır.

IEEE röleler için şu tanımı kullanır: "Girdi koşullarına kurallarla belirlenmiş bir şekilde cevap verebilecek halde tasarlanmış ve bu koşullar sağlandıktan sonra kontaklarının değişmesi veya kontrol devreleri yardımıyla ani bir değişiklik gösteren elektriksel cihazlardır."[1] Koruma röleleri için de şu tanımı kullanır: "Görevi; arızalı hatları, cihazları ve diğer anormal veya tehlikeli durumda olan güç sistemi koşullarını uygun devre kontrolü işlemini gerçekleştirmek için tespit etmek olan röleler.”[2].

Enerji dağıtım sistemlerinin temel amacı, elektrik enerjisini mümkün olan en güvenilir, en asgari kesinti sayısı ve süresi ile; en ekonomik şekilde kullanıcılara sunmaktır. Bu amaçla; meydana gelen hatalar ve arızaların hem elektrik sistemlerine ve ekipmanlara etkilerinin en aza indirilmesi hem de kullanıcıların görebileceği muhtemel zararların en aza indirilmesi için koruma ve kontrol sistemleri kullanılmaktadır. Koruma sistemleri şebekedeki elektriksel büyüklükleri takip eder ve belirlenmiş parametreler sayesinde hızlı ve güvenilir bir şekilde arızaları tespit edip gerektiğinde arızalı ekipmanları devreden çıkarırlar.

Rölelere haberleşme teknolojilerinin eklenmesi ve farklı protokollerle haberleşebilen rölelerin ortaya çıkmasıyla klasik rölelere göre daha akıllı ve etkin dijital röleler koruma sistemlerinde kullanılabilmektedir. Ayrıca rölelerin dijitalleşmesi şu gelişmeleri beraberinde getirmiştir:

- Harmonikler vb. büyüklüklerin kolayca hesaplanması

- Gerçek zamanlı verilerin okunması, işlenmesi ve uzak bölgelerle güvenilir, sağlıklı bir şekilde veri alışverişi sağlanması

- Otomatik arıza tespiti ve koruma özelliği ile sürekli iletişimde olması

Koruma sistemlerinde klasik rölelerle sağlanan geleneksel yöntemler önceden yapılmış hesaplara ve modellemelere dayanır. Bu da farklı durumlar için sabit parametreler anlamına gelir. Geleneksel yöntemler değişken durumlara adapte olamazlar ve doğru karar verme yetenekleri sınırlıdır. Klasik rölelerin yetersiz kaldığ Koruma yaptıkları sistemden haberdar olarak, ekipmanların durumu, arıza noktası, arızanın devam edip etmediği gibi bilgilere sahip bir şekilde çalıştıkları için mevcut koruma parametrelerini sistemdeki güncel duruma göre yenileyebilirler. Bu şekilde dinamik haldeki sisteme adaptif bir koruma sağlarlar.

Adaptif koruma birden çok sayıda enerji besleme durumuna sahip olan dağıtım sistemlerinde arızaların giderilmesine çözüm sunmaktadır. Adaptif koruma sistemlerindeki koruma röleleri farklı besleme durumlarına göre farklı ayar parametrelerini kullanabilir. Bu sayede adaptif koruma yöntemi, koruma sisteminin; dağıtım sisteminin o anki duruma göre en uygun parametrelerle güvenli bir 
şekilde çalışmasını sağlar. Adaptif koruma sağlandığında koruma ve kontrol iç içe geçen bir yapıda olur. Adaptif koruma bir bakıma da geri beslemeli bir kontrol sistemi olarak görülebilir. Buna örnek olarak kesicilerin tekrar kapanması verilebilir.

Arıza noktalarından ölçülen akım, gerilim, frekans gibi parametreler dikkate alınır ve buna bağlı olarak rölelerin ayar akımları ve cevap verme zamanları belirlenir. Bu durum adaptif koruma ve röle koordinasyonunda temel işlemdir. Adaptif korumada rölenin açmakapama sinyali vermesi için röle ayar değeri dinamik olarak belirlenir. Kurulu diğer röleler ile haberleşilerek onların da durumları incelenir. Bu haberleşmede, indirici merkezlerdeki standart haberleşme sistemleri için belirleyici olan IEC 61850 standardı baz alınır.

IEC 61850 standardı güç sistemleri otomasyonunda en çok kullanılan standarttır. Bu standardın ana amacı farklı üreticilerin otomasyon cihazlarının birlikte çalışabilirliğini sağlamaktır [3]. Standart, bu amaca ulaşmak için:

- Çeşitli cihazlar arasında paylaşılabilecek bilgileri tanımlayan soyut bir model sunar.

- Paylaşılabilecek bilgilere dayanan gerçekleştirilebilecek eylemleri tanıtır.

- Bilgi alışverişini uygulamak için bazı protokoller önerir.

Literatürde, rölelerin optimal koordinasyonunu sağlamak için çeşitli ağırlıklardaki kısıtlamalar dahil bir dizi Amaç Fonksiyonu geliştirilmiştir. Bu fonksiyonların performansları, en iyi fonksiyonu bulabilmek için, IEEE 30-bara sisteminde Sıralı ikinci dereceden Programlama (Sequential quadratic Programming) yöntemi ile karşıllaştırılabilmektedir [4].

Yönlü aşırı akım röleleri, iletim ve dağıtım sistemlerinin korunmasında önemli bir rol oynamaktadır. Geleneksel olarak, gerilim profili, yön koruma için polarize bir referans miktarı olarak kullanılır. Yakın sonuçlar sırasında, geleneksel röle tekniği, gerilim referans sinyalini kaybeder. Ayrıca, yöntemin uygulama maliyeti, potansiyel trafoların kurulmasını gerektirdiğinden dağıtım sistemlerinde artmaktadır. Sadece arıza sonrası akım sinyali gerektiren ve gerilim sinyali gerektirmeyen arıza yönünün tanımlanması bir yöntem olarak kullanılabilir. Arıza sonrası akım ve arıza sonrası akım fazörü baz alınan referans sinyali arasındaki açı farkı arıza yönünü belirler. [5]

Şebeke sistemindeki değişiklikleri takip edebilen röle ile adaptif koruma sağlayabilmek için faydalanılabilecek bir diğer yöntem de yapay zekâ uygulamalarıdır. Basamaklı ileri sinir ağının kullanılması (Cascade Forward Neural Network) röle eğrilerinin modellenmesi için çözümlerden biridir [6]. Yapay zekâ uygulamalarına ek olarak bulanık mantık, karar ağaçları da kullanılmıştır. Ayrıca düşük frekanslı test sinyallerinin kullanılması önerilmiş ve Dalgacık Dönüşümünün kullanılması da benimsenmiştir [7].

Akıllı şebekelerde, var olan geleneksel sistem ekipmanları olarak aşırı akım, mesafe gibi birçok koruma rölesi kullanılmaktadır. Aşırı akım röleleri koruma sistemlerinde önemli bir yere sahiptir. Aşırı akım rölelerinin karakteristiklerinden ters zaman karakteristiği, arıza akımı ayar değerinden ne kadar farklıysa çalışmadaki zaman gecikmesinin o derece kısa sürede olmasıdır. Aşırı akım rölesinin temel görevi, seçicilik özelliği gereği, herhangi bir arıza durumunda mümkün olan en kısa sürede devreye girerek arızalı bölgenin sistemden ayrılmasını ve sistemin geri kalanının sağlıklı bir şekilde çalışmaya devam etmesini sağlamaktır [8].

Güç sistemlerinde yönlü aşırı akım rölelerini optimum şekilde ayarlamak için önerilen bir başka yöntem de Gelişmiş İstilacı Yabancı Ot Optimizasyonu (Improved Invasive Weed Optimization-IWO) algoritmasıdır. Optimum röle koordinasyon problemi, doğrusal olmayan kısıtlı bir optimizasyon olarak formüle edilmiştir ve önerilen algoritma ile çözülmüş̧ür. IEEE 30 bara sisteminde test edilmiştir [9].

Yeni dağıtım sistemlerinde doğru ve hızlı arıza tespiti ön plana çıkmaktadır. Doğrusal olmayan cihazların eklenmesi, arızanın oluşma oranını arttırmışıır ve bu nedenle arızayı kısa aralıklarla tespit etme ve gidermeye ihtiyaç duyulmuştur. Akıllı cihazların dahil edilmesi arıza tespit süresini azaltmıştır. Arıza tespit algoritmalarının çoğu iterasyon ve ağ topolojisinin bir dizi varsayımını kullandığından, genellikle hesaplanan arıza mesafesi ile gerçek arıza mesafesi arasındaki fark çok büyüktür. Arıza tespitinde Petri Ağlarını kullanmak bazı avantajlar sağladığı için çok faydalı olabilir. Petri ağları iterasyonlar kullanmaz ve giriş verilerine bağlı olarak hatayı tam olarak daraltabilir [10].

Geleneksel koruma şemaları ile karşılaş̧ırıldığında, yön karşılaştırması açma süresini önemli ölçüde azaltabilir ve arıza akımının güç ekipmanı üzerindeki olumsuz etkilerini azaltabilir. Böylece koruma sistemi, açma sürelerini önemli ölçüde azaltır ve bununla birlikte, dağıtım ekipmanının ısıl gerilmesini azaltır ve yalnızca hatalı bölümlerin hızlı ve seçici tetiklenmesi nedeniyle tüm ağ boyunca gerilim düşümünü azaltır [11].

Geleneksel yönlü aşırı akım röleleri referans gerilim fazörünü, hatanın yönünü tahmin etmek için polarizasyon miktarı olarak kullanır. Yakın mesafedeki arızalarda geleneksel yön ayırt edici şema güvenilmezdir. Hat koruması için şöyle bir algoritma önerilmiştir. Polarizasyon miktarı olarak arıza öncesi akım sinyalini kullanır. Algoritma, arızanın yönünü tespit etmek için mevcut sinyalin üst üste binen bileşenini kullanır ve bu algoritma fazör tahmini gerektirmez [12].

Ağ topolojisi değişikliği, örgü ağdaki yönlü aşırı akım rölelerinin koordinasyonunu etkileyen sorunlardan biridir. Hattın bir tarafındaki rölenin hattın diğer tarafındaki röleye göre daha hızlı çalışması, ağ topolojisinin hata sırasında değişmesine neden olur ve diğer taraf rölesinden ve onun yedek rölesinden geçen kısa devre akımında değişikliğe neden olur. Bu durumda, ana ve yedek röleler arasındaki koordinasyon kısa devre akımındaki bir değişiklik nedeniyle bozulabilir. Önceki çalışmalar, topoloji değişiminden önceki kısa devre akımı ile bu sorunun üstesinden gelmek için rölelerin koordinasyonundaki topoloji değişiminden sonraki kısa devre akımı arasındaki en yüksek kısa devre akımını kullanır. Bu probleme çözüm olarak önerilen yeni bir yöntem ise Dinamik Yönlü Aşırı Akım Rölesi modeline dayanan koordinasyon yöntemidir, ağ topolojisi değişikliğinin kısa devre boyunca etkisini değerlendirmek için sunulmuştur. Bu yöntem, aşırı akım rölesi ve doğrusal programlama dinamik modelinin kullanılmasına dayanmaktadır. Bu yöntem sayesinde, rölelerin çalışma sürelerinin optimum değerleri sağlanır; ana ve yedek röleler arasındaki tüm kısıtlamalar belirlenir [13]. 
Tablo1. Mevcut Arıza Tespit yöntemlerinin avantajlarl/dezavantajları [14]

\begin{tabular}{|l|l|l|}
\hline Yöntem & Empedans & Gezen Dalgalar \\
\hline Prensip & $\begin{array}{l}\text { Gerilim ve akım, arızaya olan mesafeyle orantılı olan } \\
\text { empedansı hesaplamak için hattın bir veya iki ucunda } \\
\text { ölçülür. }\end{array}$ & $\begin{array}{l}\text { Arıza nedeniyle üretilen dalgalanma sinyali, dalganın } \\
\text { hızına ve hattın bir veya iki ucuna varma zamanına } \\
\text { bağlı olarak arıza yerini hesaplamak için kullanılır. }\end{array}$ \\
\hline Gerekli Veri & $\begin{array}{l}\text { Hat empedansı } \\
\text { Faz gerilimi ve akımı } \\
\text { Doğru hata tipi }\end{array}$ & $\begin{array}{l}\text { Hat uzunluğu } \\
\text { Dalga hızı } \\
\text { Doğru zamanlama }\end{array}$ \\
\hline Sınırlama & $\begin{array}{l}\text { Ekstra yüksek gerilim hatları için geçerli değildir. } \\
\text { Kondansatör ile kompanze edilmiş 3 terminalli hatlar } \\
\text { için geçerli değildir. }\end{array}$ & $\begin{array}{l}\text { 3 terminalli hat kullanıldığında düşük doğruluk. } \\
\text { Dengesiz ve kompanze edilmiş hatlarda düşük } \\
\text { doğruluk. }\end{array}$ \\
\hline Doğruluk & $\begin{array}{l}\text { Reaktans etkisi ve sıfır dizi karşılıklı eşleşmenin etkisi } \\
\text { nedeniyle hata gösterir. } \\
\text { Düşük ve yüksek empedans hataları için düşük doğruluk } \\
\text { verir. }\end{array}$ & $\begin{array}{l}\text { Göşük empedans hataları için düşük doğruluk. } \\
\text { verir. }\end{array}$ \\
\hline
\end{tabular}

Teknolojik gelişmeler ve piyasadaki talep nedeniyle birçok fonksiyonun tek bir donanımda biraraya getirilmesi hedefiyle tasarlanan, bu çalışmanın konusu dijital kontrol rölesi aşağıdaki özelliklere sahiptir.

- $\quad$ Ölçü, kontrol ve koruma özellikleri

- Üzerindeki tuş takımı ve haberleşme portları vasıtasıyla fonksiyonların aktif hale getirilebilmesi

- $\quad$ RS 485 portu ile IEC 60870-5-103 protokolüne uygun haberleşme olanağ

- Ethernet portu ile IEC 61850 standardına uygun haberleşme olanağı

Ayrıca, cihaz 2 ölçüm seti kullanılması; cihazın hem analizör hem de koruma ekipmanı olarak çalışmasına olanak sağlar. Cihaz bu yönleriyle mevcut dijital koruma röleleri arasında ön plana çıkmaktadır. Bu özellikleriyle literatüre katkıda buşunacaktır.

Teknolojideki ilerlemeler doğrultusunda, gelecekte şebekelerin daha fonksiyonel ve uzaktan izlenebilir; akıllı bir yapıya sahip olmaya evrileceği öngörülmektedir. Bu yeni duruma kolayca uyum sağlayabilen akıllı koruma röleleri ileride ön plana çıkacaktır. Bu kapsamda geliştirilen rölenin akıllı şebekelerde verimli bir şekilde çalışabileceği öngörülmektedir.

\section{Materyal ve Metot}

\subsection{Koruma Sistemleri}

Elektrik enerji sistemleri; işletme elemanları, tesisler ve şebeke ile elektrik enerjisini kesintisiz bir şekilde üretmek, iletmek ve dağıtmak için uygun şekilde kurulur ve işletilir. Bu amaca rağmen elektrik enerji sistemlerinde yaşanabilen istenmeyen durumlar üretimin, iletimin ve dağıtımın kesintisiz bir şekilde yapılmasına olumsuz etki etmektedir. Bu olumsuz etkiyi en düşük seviyeye getirebilmek, elektrik enerji sistemlerini ve alt bileşenlerini korumak; hedeflenen şartlarda sistemin işletilmesini sağlamak ve sistemi tehlikeye sokacak arıza durumlarında, arızalı bileşeni sistemden çıkarabilmek için kurulmuş sistemlere koruma sistemleri denir. Koruma sistemlerinin görevi, elektrik enerji sistemlerinde ortaya çıkan arızaları elektirksel ölçümlerle tespit etmek, sınıflandırmak ve mecbur kalınan durumlarda arızalı bileşeni sistemden çıkararak; sistemin sağlıklı bir şekilde çalışmaya devam etmesini sağlamaktır [15]. Bu nedenle koruma sistemleri uygun şekilde kurulmuş olmalı ve sürekli çalışır durumda olmalıdır. Koruma sistemlerinden aşağıdaki özellikleri taşıması beklenir.

1. Seçicilik

2. Süratli çalışma

3. Güvenilirlik

4. Yedek koruma

5. Kararlılık

6. Ekonomiklik

Koruma sistemleri aşağıdaki bileşenlerden meydana gelmektedir:

- Kesiciler,

- Ölçü transformatörleri,

- Koruma röleleri,

- Yardımci ekipmanlar 


\subsubsection{Koruma Sistemlerinde Röleler}

Röleler giriș uçlarından aldıkları elektriksel sinyale göre çıkıș uçlarından elektriksel bir tepki verirler. Röleler, çıkıș kontakları vasıtası ile verdikleri bu tepki ile bir elektrik devresini kontrol ederler. Koruma sistemlerinde rölelerin, arıza durumlarında aldıkları elektrik sinyalleri ile çalışma akışları Şekil 1'deki gibidir.

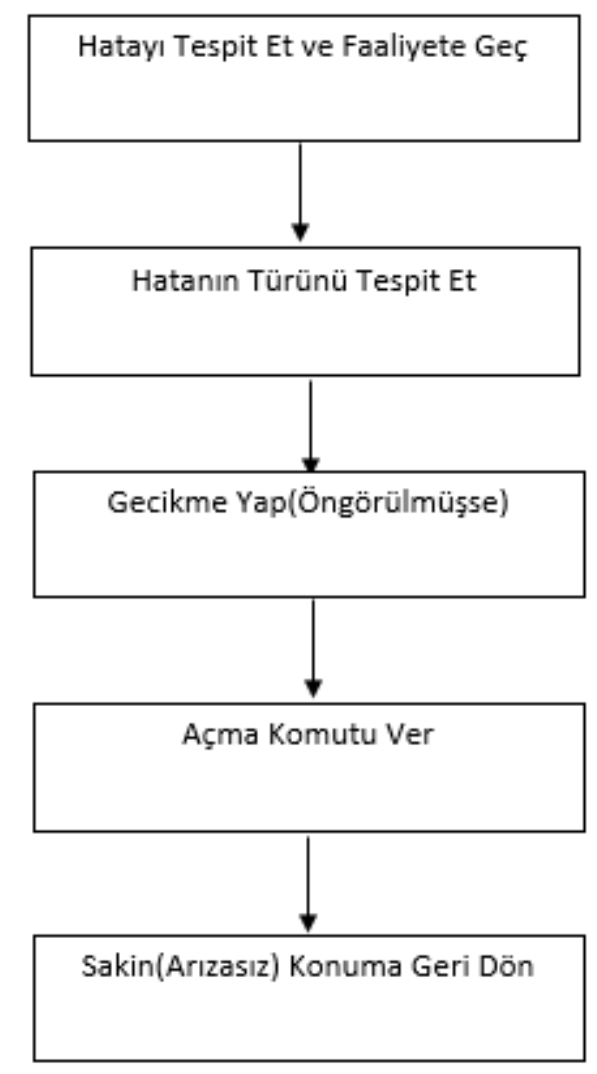

Şekil 1. Koruma rölelerinin arıza durumlarındaki çalışma akışı [8]

Koruma röleleri elektriksel sinyalleri alıp ayarlanan değerlerle karşılaştırıp bu karşılaştırmaya göre çıkış veren cihazlardır. Elektriksel girişler akım, gerilim, direnç ya da farklı olarak sıcaklık olabilir. Röle çıkışları ise görsel bildirim için ışık ya da sesli uyarı, ekranlarda değer bildirimi, haberleşme sinyalleri, kontrol uyarıları ya da enerjiyi açma kapama için kesiciye gönderilen sinyal olabilir.

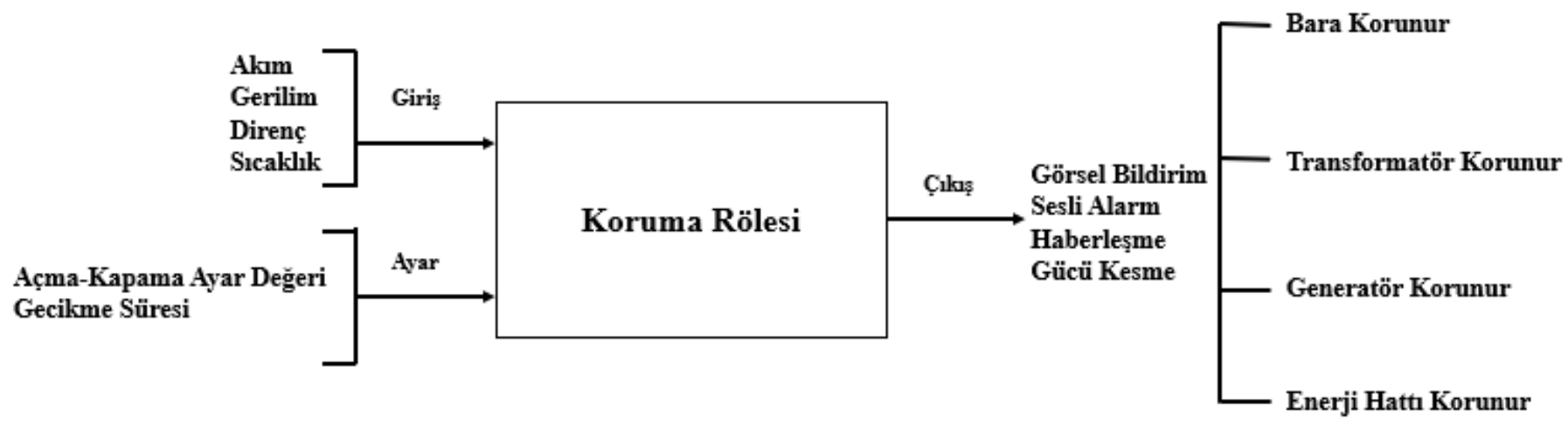

Şekil 2. Koruma Rölesi giriş ve çıkışları

Koruma röleleri oluşabilecek arızalara veya aşırı yüklenmelere sistemin sağlıklı çalışması için koruma görevi üstlendiklerinden taşıdıkları önem yüksektir. Generatör, transformatör, bara, hat gibi şebeke elemanlarında oluşabilecek kısa devre veya izolasyon hatasıyla oluşabilecek aşıı akım, aşırı gerilim arızalarının verebileceği zararlara karşı sistemi ve sistemin alt bileşenlerini röleler korur [16]. 
Koruma röleleri, teknolojilerine göre klasik röleler ve dijital röleler olarak ikiye ayrılır. Klasik ve dijital röleler karşılaştırıldığında,

- Dijital koruma röleleri birden fazla fonksiyonu tek bir donanın içerisinde gerçekleştirebilirken klasik röleler bu fonksiyonları gerçekleştirebilmek için ek ekipmanlara ihtiyaç duyarlar.

- Dijital koruma röleleri haberleşme özellikleri sayesinde diğer cihazlarla haberleşebilir. Bu yüzden otomasyona daha elverişlidir.

- Dijital koruma rölelerine, yazılımlarını güncellemek vasıtası ile, yeni fonksiyonlar kazandırılabilir. Klasik rölelerde ise bu mümkün değildir.

- Herhangi bir arıza durumunda dijital rölelerin açma ve normale dönme süreleri klasik rölelere göre daha kısadır.

- Dijital koruma röleleri klasik rölelere göre daha az bileşen içerdiği için daha az enerji tüketirler.

- Dijital röleler, herhangi bir arıza durumunda; arıza öncesi ve arıza anında akım, gerilim, frekans gibi elektriksel değerleri kaydettiği bir hafızaya sahiptir ve bu değerle ile sürekli hesaplama yapar.

- Dijital röleler sürekli kendilerini kontrol ederler. Kendi arızaları varsa bildirirler. Dijital rölelerin sürekli yazılımlarını ve donanımlarını otomatik olarak kendileri kontrol etmeleri bakım maliyetlerini azaltır.

- Dijital rölelerde mikroişlemci teknolojisi ve gömülü yazılım olduğu için ölçüm doğruluğu ve güvenilirlik klasik rölelere göre daha yüksektir.

- Dijital rölelerin çalışması menü-tabanlı olduğu için kullanımı basit ve güvenilirdir. Sahip olduğu ekran sayesinde arıza durumu ve arıza ile ilgili bilgiler, arıza değerleri rahatlıkla izlenebilir. Bu değerler kayıt altına alınıp bilgisayar vasıtası ile rapor haline de getirilebilir.

- Dijital rölelerin elektriksel dayanımları daha fazladır ve harmoniklerden etkilenmemeleri için filtreleri mevcuttur.

Alçak gerilim seviyesinde koruma rölesinin kumanda ettiği açma-kapama elemanı kontaktör, orta ve yüksek gerilim seviyesinde ise kesicidir. Koruma fonksiyonlarına göre çeşitli koruma röleleri bulunmaktadır. Bunlar,

- Aşırı akım koruma rölesi

- Düşük ve yüksek gerilim koruma rölesi

- Diferansiyel röleler

- Mesafe(empedans) röleleri

- Toprak kaçağı röleleri

olarak sıralanabilir. Eelektrik enerji sistemlerinde en yaygın olarak aşırı akım rölesi ve mesafe rölesi kullanılır.

Aşırı Akım Rölesi: Aşırı akım rölesi sisteme bir ölçü transformatörü üzerinden bağlanır. Ölçtüğü değer ayarlanan değerden yüksek ise kesiciye açma sinyali gönderir ve arızayı sistemden ayırır. Aşırı akım rölelerinin farklı üreticileri olsa da çalışma prensibi temelde aynıdır. Sabit ve ters zamanlı olarak iki farklı tipteki çalışma prensibine sahip aşırı akım rölelerinin arasındaki tek fark açma zamanının ayarlanması ile ilgilidir.

1. Sabit Zamanlı Aşırı Akım Rölesi (Bağımsız Karakteristikli): Açma zamanı sabittir. Arıza akımı değerinden ve arıza mesafesinden bağımsız olarak sabit sürede açma yapar.

2. Ters Zamanlı Aşırı Akım Rölesi (Bağımlı Karakteristik): Açma zaman gecikmesi sabit değildir. Akım değerine ve zaman çarpanına bağlıdır. Akım değeri arttıkça açma süresi kısalır. Bu bakımdan avantajlıdır.

Aşırı akım röleleri koruma sistemlerinde en çok kullanılan rölelerdir. Aşırı akım röleleri, koruma sisteminde en iyi seçiciliği ve en iyi koordinasyonu sağlamak için kararlı durumdaki kısa devre simülasyonlarına göre ayarlanır. Fakat bazı durumlarda, tüm arıza senaryolarını kapsayacak şekilde aynı fonksiyonellik altında birden çok ayar tanımlamak gerekmektedir. Manuel müdahaleleri önlemek için ayarlarını otomatik değiştirebilen daha adaptif rölelere ihtiyaç vardır [17].

Yönlü Aşırı Akım Rölesi: Yönlü aşırı akım röleleri sadeliği, maliyet etkinliği ve doğruluğu nedeniyle tercih edilir. Yönlü aşırı akım röleleri, akımın halka(ring) ana sistemler için fiderlerin her iki tarafindan beslendiği yerlerde, paralel fiderlerde kullanılır. Bu gibi durumlarda röle elemanının, yanıt vermesi gereken hataları ve sınırlandırması gereken diğer parametreleri ayırt etmek için ek bir belirleyicilik özelliği bulunmalıdır. Ayrıca, 'seçicilik', yalnızca hata akımlarının büyüklüğüne bağlı olması durumunda yeterli olmayacaktır. İşlem için akım ve faz açısı değerleri gerekir. Böylece iki ayrı gerilim ve akım sinyali, akım ve faz açısının büyüklükleri hesaplanabilir ve bir girdi olarak alınabilir [18]. Böylece akım yönüne bağlı olarak arıza yönü tespit edilir ve yalnızca arızalı bölüm sistemden ayrılır.

Mesafe Rölesi: Mesafe röleleri sisteme bağlı oldukları ölçü transformatörleri üzerinden aldıkları akım ve gerilim bilgileri ile bir empedans değeri hesaplarlar. Bu empedans değerindeki değişime göre önceden ayarlanmış gecikme süresine uygun bir şekilde koruma görevlerini yerine getirirler. Ölçülen bilgilerle hesaplanan empedans değeri, arıza noktasının röleye olan mesafesine bağlıdır. Empedans değeri hattın uzunluğu ile doğru orantılıdır [19]. 
Akill Şebekelerde Koruma Röleleri

Akıllı şebeke, dijital bilgi ve iletişim teknolojisini kullanan modern elektrik şebekesini ifade eder. Akıllı Şebeke, geleneksel şebekedeki elektrik ve bilgi sistemlerinden gelen geleneksel tek yönlü akış yerine, dijital elektrik teknolojisine sahip bir hizmet sağlayıcı ile müş̧eriler arasında, iki yönlü bir iletişim ve enerji akışı oluşturur. Akıllı şebekeler, akıllı bağlantılarla güvenli, ekonomik ve sürdürülebilir akıllı bir elektrik ağıdır [20].

Geleneksel şebeke ve akıllı şebeke karşılaştırıldığında akıllı şebekelerin avantajları ön plana çıkmaktadır [21].

- Hataları ön görüp engelleyebilir.

- Tehlikelerden ve tehditlerden emindir.

- Son kullanıcı ve piyasa ile etkileşimlidir.

- Hem varlıklara hem de verilere göre dağıtılmıştır.

- Öngörülen / tespit edilen sorunları düzeltmek / ayırmak için kendi kendini iyileştirebilir.

- Kaynakların verimli kullanımını sağlamak için optimize edilebilir.

- Verileri bilgiye dönüştürebilir.

Ayrica;

- Akıllı şebekeler tamamen koordinasyona sahip, üretken ve güvenilir bir modda yönetilir. Teknoloji sayesinde otomasyondan faydalanılır. Anlık değişimlere hızlıca yanıt verir.

- "Kendini kontrol etme ve iyileştirme" özelliği sayesinde sistemdeki talep edilen enerjiyi karşılar, süreklilik sağlar ve güven oluşturur.

- Çok sayıda son kullanıcıya hizmet vermesi durumunda ve ilerleyen dijital ekonomi teknolojileri ile ortaya çıkan verinin uygun, zamanında ve güvenli bir şekilde akışını sağlayan bu verilerin keşfedilmesini ve işlenmesini sağlayan bir platforma olanak sunar.

Akıllı şebekelerde değişen işletim koşullarına ve yük akışına göre uygun koruma sistemi kurabilmek için hızlı ve güvenilir ekipmanlara ihtiyaç vardır. Yük akışının yön değiştirmesi durumuna uyum sağlayabilen, seçicilik özelliğine göre farklı arızaları ayırt edebilen ve oluşabilecek geniş çaplı elektrik enerjisi kesintilerini önceden tahmin edip farklı açma kapama karakteristikleri sergileyebilen bir akıllı sistemin, akıllı şebekelerde koruma görevini yerine getirmesi gerekmektedir. Bu şekilde, arızalar daha iyi kısıtlandırılarak daha verimli ve daha aktif bir koruma sağlanır. Sistem ekipmanları üzerindeki yük azaltılır. Akıllı şebekelere uyumlu yeni nesil koruma sistemlerinin geliştirilmesiyle akıllı şebekelerin değişken işletim koşullarına uyum sağlayabilecek adaptif bir koruma ve kontrol sağlanması önemli bir konudur.

\section{Araştırma Sonuçları ve Tartışma}

\subsection{Geliştirilen Dijital Koruma Rölesi}

Teknolojik gelişmeler doğrultusunda ve piyasadaki talep nedeniyle birçok fonksiyonu tek bir donanımda bir araya getirebilmek için yeni bir dijital koruma rölesi geliştirilmesi hedeflenmiştir. Bu rölenin hedeflenen özellikleri aşağıdaki gibidir:

- Elektrik dağıtım şebekelerinde kullanılmak üzere kontrol, ölçü ve koruma fonksiyonları içermesi,

- Fonksiyonların, röle üzerindeki tuş takımı ve haberleşme portları üzerinden aktif hale getirilebilmesi,

- Doğrudan akım trafosuna bağlanabilmesi,

- RS 485 portu ile IEC 60870-5-103 protokolünü kullanarak iletişim yapabilmesi,

- USB portuna sahip olmas1,

- Ethernet portu ile bir otomasyon sistemi içerisinde IEC 61850 standardına uygun haberleşme özelliklerini sağlaması

Hedeflenen cihazda 2 ölçüm seti kullanılarak ürünün hem analizör hem de koruma ekipmanı olarak çalışması sağlanmıştır. Cihaz aşağıdaki koruma özelliklerini tek bir donanımda sunmaktadır.

Auto reclose: Hatanın ortadan kalması durumunda rölenin güvenli bir şekilde devreye alınmasıdır.

Fault locater: İletim hattının bilinen karakteristikleri kullanılarak hatanın hangi mesafede olduğununun bulunmasıdır.

Cold load pick up: Bir dağııım şebekesi tekrar enerjilendiği zaman oluşan aşırı akım durumunun değerlendirilmesi, soğuk yük üzerine kapatabilmesidir.

Yönlü koruma: Korumanın hatanın oluştuğu yöne göre uygulanmasıdır.

Thermal overload: Bilinen trafo karakteristiklerine göre sıcaklığın ne zaman yükseleceğinin hesaplanmasıdır.

Sistemde kullanılması gereken transformatörler hariç her şeyin tek bir cihaz içerisinde olup kullanılması kolay bir ürün olması hedeflenmiştir. 
Ürün geliştirilirken kullanılan yöntemler aşağıdaki gibidir:

- Geliştirilen üründe sayısal işaretlerin, röle karakteristiklerinin, set değerlerinin, kararlarının saklanması ve yazılımın işlenmesi için, digital giriş çıkış ve haberleşme birimlerine sahip mikroişlemci kullanılmış ve programlanamıştır.

- Enerji dağıtım şebeklerindeki akım ve gerilim ölçümü için donanım tasarımı sırasında manyetik değişkenlerin ölçümü ve kontrolü yöntemi kullanılmıştır.

- Koruma sistemlerine uygun özellikleri taşıyabilmesi için algoritmlar geliştirilmiştir.

- Cihaza bilgisayar ile uzaktan bağlanabilme, izleme ve konfigüre edebilme özelliklerini sağlayabilmek için çeşitli haberleşme protokollerine uygunluk sağlanmıştır.

Laboratuarda yapılan testler dışında cihaz sahada dört farklı noktaya yerleştirilmiş ve sahadan gelen geri bildirimlere göre güncellenmiştir. Cihazı yerleştirildiği noktalar:

- Sancaktepe Operasyon Merkezi

- Tuzla'da bir trafo merkezinde bir hücre

- OG hücre Fabrikası / Ankara

- OG Hücre ve Trafo Fabrikası / Ankara

Cihaz prototip üretimi gerçekleştikten sonra DATAKOM Elektronik Mühendislik Anonim Şirketi’nin kazandığı Ar-Ge yetkinliklikleri şunlardır:

- Üzerinde çalışılan IEC 60870-5-103 standardına uygun haberleşme başlı̆̆ı ile işletim sistemi olmayan bir cihazda çoklu-görev çalışması gerçekleştirilmiştir.

- Tek bir üründe toplanan koruma fonksiyonları aşağıdaki gibidir:

- Düşük gerilim koruma (27)

- $\quad$ Arıza yeri tespit edici (FL)

- $\quad$ Aşırı gerilim koruma $(59 \mathrm{~N})$

- Termik koruma (49)

- $\quad$ Açma devresi denetimi (74TCS)

- IEC 61850 standardına uygun haberleşme özelliği Datakom ürün tasarımları arasına bu ürün ile girmiştir. Temel olarak gerçekleştirilmiş, Datakom Haberleşme protokolleri arasına kazandırılmıştır.

Elde edilen dijital koruma rölesi, modern teknolojiyi kullanan, standart panelmetre boyutlarında, renkli ekranlı ve yönlü bir koruma rölesidir. Düşük derinliği sayesinde panoda yer tasarrufu sağlamaktadır. Cihaz hassasiyet, kullanım kolaylığı ve esneklik özelliklerini güvenilir ve düşük maliyetli bir tasarımla birleştirir.
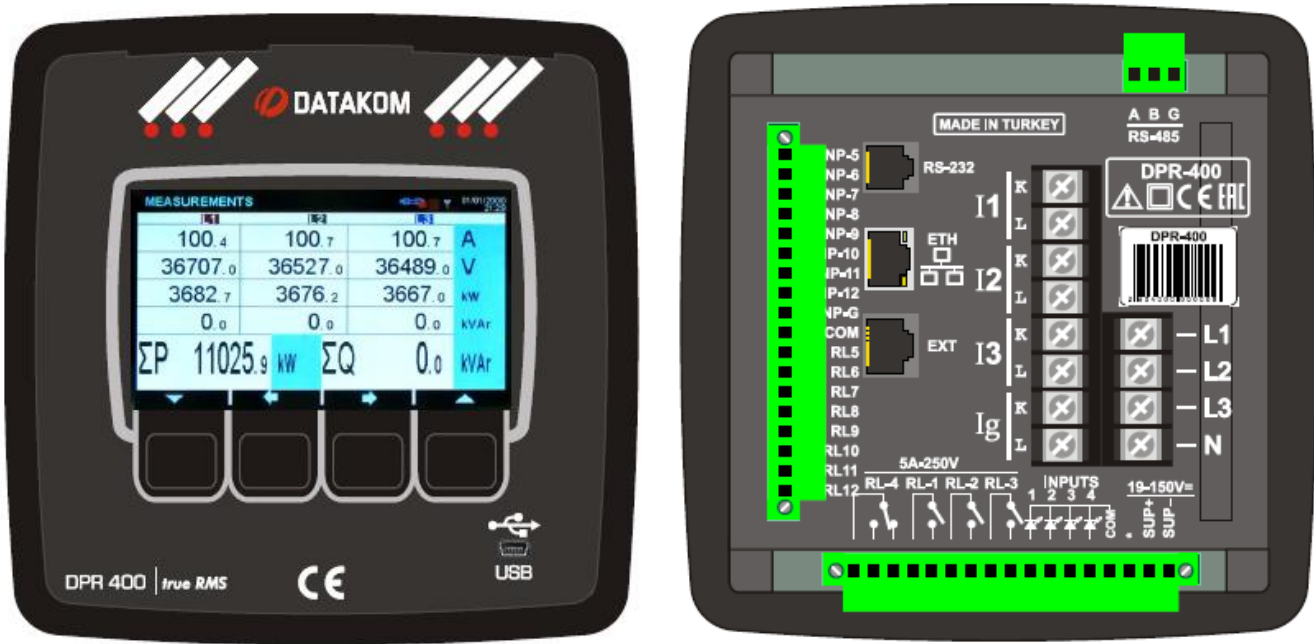

Şekil 3. Dijital koruma rölesinin ön ve arka yüzden görünümü 
Cihazın katalog özellikleri aşağıdaki gibidir:

- Çift devreli akım ölçüm girişleri sayesinde cihaz, hem \%0,5 hassasiyet sınıfı bir analizör, hem de 50xIn ölçebilen bir koruma rölesidir.

- Cihaz hassas koruma sağlamak için çeşitli koruma eğrilerine sahiptir. Birden fazla koruma eğrisi aynı anda aktif edilebilir durumdadır.

- Cihazın 4.3 inç boyutundaki renkli ekranında birçok ölçüm aynı anda izlenebilmektedir. Büyük ekran, kullanım kolaylığı ve birçok bilgiye ulaşmayı sağlar.

- Cihaz USB, izole RS-485 ve Ethernet portları sayesinde çeşitli SCADA sistemlerine kolayca bağlanır ve uzaktan izlemeye olanak sağlar.

- RS-485 üzerinden MODBUS ve IEC60870-5-103 haberleşme protokollerini destekler.

- Ethernet portu üzerinden ise MODBUS TCP/IP ve IEC61850 protokollerini destekler.

- Parametre ayarı ön paneldeki tuşlardan veya ücretsiz verilen PC programı ile yapılır. Program cihaza USB, RS-485 veya istenirse internet üzerinden bağlanır. Ayrıca USB portu üzerinden de yazılım güncellemesi yapılabilmektedir.

- Cihazın röle çıkışlarından iki tanesi bağlantı izleme özelliğine sahiptir. Bu çıkışlar yük devresinin devamlılığını sürekli kontrol eder, devre açılırsa alarm verir.

- Cihaz 1MB dahili hafizasına 20 adede kadar COMTRADE formatında osilografik kayıt alır.

- Cihaz endüstri ürünleri için güvenlik, EMC, titreşim ve çevre standartlarını karşılar.

\section{Sonuç}

Üretim, iletim, dağıtım ve tüketimden meydana gelen elektrik enerjisi sisteminde, alt bileşenlerin ve tüketicilerin arızalardan korunması ve elektrik enerjisi kalitesinin sağlanması için koruma sistemlerinin görevlerini, doğru ve seçici bir şekilde çalışarak süreklilikle yerine getirmeleri gerekmektedir. Ancak üretimden tüketime kadar oluşan bu süreçte koruma sistemleri bazı hatalarla/arızalarla karşılaşmaktadır. Etkili oldukları bölgelerde işletme koşullarının değişmesi, koruma sistemlerinin farklı arızalara maruz kalmasına neden olmaktadır. Mevsimsel tüketim değişiklikleri, işletmelerdeki besleme yönünün değişmesi gibi farklı durumlarda farklı uyumluluk gösterebilecek adaptif koruma sistemleri yeni nesil şebekelerin sürdürülebilirliği için gereklidir. Adaptif korumanın gerçekleştirilebilmesi için koruma sisteminin en çok öneme sahip elemanlarından biri olan koruma rölelerinin yüksek teknoloji içeren, birçok koruma özelliğini bir arada bulunduran akıllı donanımlar olmaları gerekmektedir.

$\mathrm{Bu}$ çalışmada birçok koruma fonksiyonunun tek bir donanımda sunulduğu bir dijital koruma rölesinin tasarımı, gerçeklenmesi ve test edilmesi ile elde edilen sonuçlar verilmiştir. Bu kapsamda;

- Elde edilen dijital koruma rölesinde toplanan koruma fonksiyonları aşağıdaki gibidir:

- $\quad$ Düşük gerilim koruma (27)

- $\quad$ Arıza yeri tespit edici (FL)

- $\quad$ Aşırı gerilim koruma (59N)

- $\quad$ Termik koruma (49)

- $\quad$ Açma devresi denetimi (74TCS)

- Elde edilen koruma rölesi, standart prosedüre göre test edilmiştir. Laboratuar ve saha testleri tamamlanmıştır. Alçak Gerilim Direktifine ve Elektromanyetik Uyumluluk Yönetmeliğine uygundur ve gerekli sertifikalar alınmıştır.

- Test sonuçları, elde edilen rölenin ölçümleri ve hesaplamaları doğru yaptığını, doğru zamanda açma-kapama işlemini gerçekleştirdiğini göstermektedir.

- Geliştirilen röle yazılımı hatalı/arızalı durum ile sağlıklı durumu ayırt edebilmektedir.

- IEC 61850 ve MODBUS haberleşme protokollerine uygunluk gerçekleştirilmiştir.

- Cihaz, SCADA uzaktan izleme ve kontrol yazılımları ile uyumlu çalışmaktadır.

e-ISSN: 2148-2683 
Mevcut röle, gelecek çalışmada daha da geliştirecektir. Özellikle arıza noktası belirlerme özelliğinin iyileştirilmesi ve hat kopukluğu arızasını tespit edebilme özelliğinin eklenmesi planlanmaktadır. Hat kopukluğu uzun süreli enerji kesintilerine neden olan bir arızadır. Hattın her iki noktasından da çevrimiçi ölçümler yapılarak hat akımının 0 A olduğu durumlar takip edilip arıza durumları tespit edilecektir. Ayrıca yapılan ölçümlerle arıza noktasını tespit etme çalışmaları da yapılacaktır. Arıza noktasının röle tarafından tespit edilmesi zaman kaybını önleyecek bir çalışma olacaktır. Böylece mevcut dijital koruma rölesi planlandığı şekilde geliştirildiğinde endüstride ve literatürde daha da önemli bir yer edinecektir.

\section{Ek Bilgi}

Bu çalışma TÜBİTAK 3160576 nolu "Elektrik Dağıtım Şebekelerinde Kullanılmak Üzere Çok Fonksiyonlu Dijital Aşırı Akım Rölesi Tasarımı ve Geliştirilmesi” isimli proje kapsamında desteklenmiş olup DATAKOM A.Ş. iş birliği ile yapılmışıtır.

\section{Kaynakça}

[1] IEEE C37.90 (2006). IEEE Standard for relays and relay systems associated with electric power apparatus, The Institute of Electrical and Electronics Engineers, New York, USA.

[2] IEEE 100 (1996). The IEEE standard dictionary of electrical and electronics terms, The Institute of Electrical and Electronics Engineers, New York, USA.

[3] Alvarez de Sotomayor, A., Della Giustinaa, D., Massa, G., Dedè, A., Ramos, F., Barbatoa, A. 2018. IEC 61850-based adaptive protection system for the MV distribution smart grid, Sustainable Energy, Grids and Networks (15), 26-33

[4] J. Shah, N. Khristi, V. N. Rajput and K. S. Pandya, A comparative study based on objective functions for optimum coordination of overcurrent relays, 2017 7th International Conference on Power Systems (ICPS), 2017, Pune, India

[5] Kiaei, I., Lotfifard, S., Ghanaatian, M. 2019. Current-only Directional Overcurrent Protection Using Postfault Current. 2019 IEEE Texas Power and Energy Conference (TPEC), February 2019, TX, USA

[6] A. Sahrin, A. Tjahjono, M. Pujiantara and M. H. Purnomo, The modeling of directional overcurrent relay in loop system using cascade forward neural network, 2017 International Seminar on Intelligent Technology and Its Applications (ISITIA), Surabaya, 2017, 69-74.

[7] A. N. Milioudis, G. T. Andreou and D. P. Labridis, 2015. Detection and Location of High Impedance Faults in Multiconductor Overhead Distribution Lines Using Power Line Communication Devices, IEEE Transactions on Smart Grid(6), no. 2, 894-902

[8] Ateş, Y. 2016. Dağıtık Üretim Tesisleri İçeren Şebekeler İçin Akıllı ve Adaptif Bir Koruma Metodunun Geliştirilmesi. Yıldız Teknik Üniversitesi, Fen Bilimleri Enstitüsü, Doktora Tezi, 123s, İstanbul

[9] Srinivas, S.T.P., Shanti Swarup, K. 2019. Application of improved invasive weed optimization technique for optimally setting directional overcurrent relays in power systems, Applied Soft Computing (79), 1-13

[10] Sreerama, R., Swarup, K. S. 2017. Detection, localization and fault diagnosis using PetriNets for smart power distribution grids, 2017 7th International Conference on Power Systems (ICPS), 2017, Pune, India

[11] M. Baňas, M. Höger and J. Altus, "Application of the directional overcurrent relays with directional comparison system in medium voltage networks," 2018 19th International Scientific Conference on Electric Power Engineering (EPE), Brno, 2018, pp. 1-6.

[12] Nojavan, M., Seyedi, H., Mehdinejad, M. 2016. A novel scheme for current-only directional overcurrent relay, International Journal of Electrical Power \& Energy Systems (82), 252-263

[13] Mohammadzadeh, N., Mohammadi, R., Mahdi, C., Maleki, G. 2019. Optimal coordination of directional overcurrent relays considering two-level fault current due to the operation of remote side relay, Electric Power Systems Research (175)

[14] Abu-Siada, A., Mir, S. 2019. A new on-line technique to identify fault location within long transmission lines, Engineering Failure Analysis (105), 52-64

[15] Doğancı A.Ç. Elektrik Dağıtım Sistemlerinde Adaptif Koruma. İstanbul Teknik Üniversitesi, Fen Bilimleri Enstitüsü, Yüksek Lisans Tezi, 83s, İstanbul

[16] Arıkan, O., Aydın, H., Gürsanlı, Ö. Yüksek Gerilim Enerji İletim Hatlarını Koruma Uygulaması, Güç Sistemleri Konferansı, İstanbul 2016

[17] Momessoa Antonio E.C., Maycon S. W., Eduardo B., Asadaa N. 2019. Fuzzy adaptive setting for time-current-voltage based overcurrent relays in distribution systems, International Journal of Electrical Power \& Energy Systems (108), 135-144

[18] R. Agarwal, T. G. Arora and R. Tiwari, "Designing of Numerical Directional Overcurrent Relay," 2018 International Conference on Smart Electric Drives and Power System (ICSEDPS), Nagpur, 2018, pp. 186-191

[19] Bayrak, M., Usta, Ö. 2003. Adaptif Mesafe Rölesi, Elektrik-Elektronik-Bilgisayar Mühendisliği 10. Ulusal Kongresi, İstanbul 2003

[20] Keyhani, A. 2011. Design of Smart Power Grid Renewable Energy Systems. Wiley Publication, 560s, Singapur.

[21] Pehlivanoğlu Gürbüz, K. 2019. Smart Grid Applications and Technologies in Distribution Systems, Ortadoğu Teknik Üniversitesi, Fen Bilimleri Enstitüsü, Yüksek Lisans Tezi, 126s, Ankara 